\title{
Autophagy and Cancer Therapy
}

\author{
Andrew Thorburn, Douglas H. Thamm, and Daniel L. Gustafson \\ Department of Pharmacology, University of Colorado School of Medicine, Anschutz Medical Campus, Aurora, \\ Colorado (A.T.); and Flint Animal Cancer Center, Department of Clinical Sciences, Colorado State University, \\ Fort Collins, Colorado (D.H.T., D.L.G.)
}

Received January 15, 2014; accepted February 26, 2014

\begin{abstract}
Autophagy is the process by which cellular material is delivered to lysosomes for degradation and recycling. There are three different types of autophagy, but macroautophagy, which involves the formation of double membrane vesicles that engulf proteins and organelles that fuse with lysosomes, is by far the most studied and is thought to have important contextdependent roles in cancer development, progression, and treatment. The roles of autophagy in cancer treatment are complicated by two important discoveries over the past few
\end{abstract}

years. First, most (perhaps all) anticancer drugs, as well as ionizing radiation, affect autophagy. In most, but not all cases, these treatments increase autophagy in tumor cells. Second, autophagy affects the ability of tumor cells to die after drug treatment, but the effect of autophagy may be to promote or inhibit cell death, depending on context. Here we discuss recent research related to autophagy and cancer therapy with a focus on how these processes may be manipulated to improve cancer therapy.

\section{Introduction}

Autophagy is the process by which proteins, organelles, and other cellular components are delivered to the lysosome for degradation and recycling (Mizushima, 2007; Ravikumar et al., 2010). Although autophagy was first described over 40 years ago, the last decade has seen an explosion of interest (Yang and Klionsky, 2010a) and the clear connection of autophagy to various diseases (Rubinsztein et al., 2012) and diverse stresses (Kroemer et al., 2010), as well as normal developmental processes (Levine and Klionsky, 2004) and aging (Rubinsztein et al., 2011).

Three types of autophagy have been characterized. Macroautophagy involves the formation of double membrane vesicles that engulf proteins and organelles, such as mitochondria and peroxisomes. These vesicles, called autophagosomes, fuse with lysosomes and the lysosomal hydrolases then degrade the engulfed material, allowing macromolecular precursors, such as amino acids, to be recycled and used as metabolic intermediates. In the literature, it is sometimes confusing as to whether increased numbers of autophagosomes are actually indicative of increased autophagy, i.e., more

This work was supported by grants from the National Institutes of Health National Cancer Institute [Grants R01-CA111421, R01-CA150925, and P30 CA046934]

dx.doi.org/10.1124/mol.114.091850. autophagic flux whereby autophagosomes fuse with lysosomes and their contents are degraded. This is because autophagosomes can increase in a cell either because more are being made or because fewer are fusing with lysosomes and being degraded. Many published experiments do not distinguish between these two diametrically opposed conclusions, and this may explain some contradictory results that have been reported over the years. Chaperone-mediated autophagy (CMA) involves direct recognition of specific proteins that contain an exposed amino acid motif (KFERQ) that is recognized by the heat shock protein hsc70 and then delivered directly to the lysosome via the lysosomal protein LAMP2A. Finally, microautophagy involves direct engulfment of material by the lysosome. By far the best studied of these processes is macroautophagy, and almost all the work related to autophagy and cancer development, progression, and therapy refers to macroautophagy. However, recent work shows that CMA is important for tumor growth and progression (Kon et al., 2011) and, thus, could potentially be a useful therapeutic target in cancer. Additionally, current pharmacological methods to inhibit autophagy that target the lysosome may affect CMA as well as macroautophagy (Thorburn and Debnath, 2011). Thus, although in this review we will use the term "autophagy" to mean macroautophagy, the reader should bear in mind that CMA is also important and may also be targeted

ABBREVIATIONS: ABT737, 4-[4-[[2-(4-chlorophenyl)phenyl]methyl]piperazin-1-yl]- $N$-[4-[[(2R)-4-(dimethylamino)-1-phenylsulfanylbutan-2-yl]amino]3-nitrophenyl] sulfonylbenzamide; BECN, Beclin 1; CMA, chaperone-mediated autophagy; CQ, chloroquine; EGFR, epidermal growth factor receptor; FasL, Fas ligand/CD95; HCQ, hydroxychloroquine; IL, interleukin; RAS, rat sarcoma viral oncogene homolog; TRAIL, tumor necrosis factor like apoptosis-inducing ligand. 
in at least some studies where autophagy is manipulated in an attempt to improve cancer treatment.

Mammalian autophagy is controlled by a complicated network of signaling pathways, most of which feed into the PI3K/mTORC1 pathway. These signaling pathways regulate the evolutionarily conserved core autophagy machinery that involves over 30 autophagy regulators encoded by ATG genes (Ravikumar et al., 2010; Yang and Klionsky, 2010b). In simplified terms, the autophagy machinery can be broken into various interconnected steps (for review of the role(s) of ATG proteins in these steps see Mizushima et al., 2011). First there is activation of a complex involving the serine/threonine kinase ULK1. This complex is a direct target of the mTOR pathway, as well as other regulators of autophagy, specifically AMP-activated protein and serves to initiate formation of the autophagosome. Expansion of the autophagosomal membrane is promoted by a second multiprotein complex controlled by a scaffold protein, Beclin 1 (BECN1), which involves activation of a lipid kinase, VPS34. Continued expansion of the membrane also relies on various proteins that orchestrate the conjugation of two proteins (ATG5 and ATG12) and a protein-lipid conjugation event whereby ATG8, often known as LC3 in mammalian cells is, along with its family members, conjugated to phosphatidylethanolamine. The expanding membrane engulfs cargo. This occurs both selectively through the actions of scaffolding proteins that contain a socalled LIR domain, such as p62/SQSTM (Birgisdottir et al., 2013), and nonselectively. The autophagosomal membrane then fuses to form an intact autophagosome, which is often detected by following foci that stain positive with LC3, and autophagosomes are transported to close vicinity with lysosomes, to which they fuse through a mechanism that requires the activity of small GTPases, especially RAB7 and SNARE-like proteins. This fusion creates an autolysosome, which degrades the contents of the original autophagosome and macromolecular precursors are then recycled back to the cytoplasm.

A large body of work over the past few years has linked autophagy to cancer and cancer therapy (for recent reviews see Kimmelman, 2011; White, 2012; and Lorin et al., 2013). Three central questions must be considered regarding autophagy and cancer therapy: should we try to inhibit or stimulate autophagy to make cancer treatment better? Will some people benefit from treatments that affect autophagy and some not? And, if we are going to inhibit or stimulate autophagy, what is the best way to do so? Answers to these questions are urgently needed because we are already manipulating autophagy in cancer patients. Most of this manipulation is inadvertent-as discussed below, almost all cancer therapies can affect autophagy to some degree, most likely in both tumor and normal cells. However, there are also more than three dozen ongoing clinical trials listed on the ClinicalTrials.gov Web site where autophagy is being deliberately manipulated in cancer patients. In all cases so far, these trials are trying to inhibit autophagy, and the results of the first five phase I human cancer trials as well as a phase I clinical trial in canine cancer patients from our group will be reported soon. In this review, we discuss some recent discoveries and ideas about the roles of autophagy in cancer therapy in an attempt to answer the questions posed above and identify some of the important issues and problems that still need to be better addressed.

\section{Cancer Therapy Effects on Autophagy: Inhibition and Activation}

Many cancer drugs as well as ionizing radiation affect autophagy (Levy and Thorburn, 2011). In most cases, treatment increases autophagy. For example, in a screen of 80 cytotoxic anticancer agents that caused high levels of autophagosome accumulation, 21 induced higher numbers of autophagosomes but not increased autophagic flux (i.e., these agents most likely block autophagy by inhibiting fusion with the lysosome), whereas 59 induced both autophagosome formation and flux and, thus, truly increased autophagy (Shen et al., 2011). To add confusion, some agents can both increase the formation of autophagosomes and block their fusion with lysosomes (Köchl et al., 2006; Ganley et al., 2011).

Diverse classes of anticancer drugs including DNA damaging agents, microtubule-targeted drugs, antimetabolites, death receptor agonists, hormonal agents, antiangiogenic agents, proteasome inhibitors, histone deacetylase inhibitors, and kinase inhibitors have all been shown to affect autophagy. Indeed, as yet there are no known classes of anticancer agents that have been clearly demonstrated not to affect autophagy. Somewhat surprisingly, in many cases the molecular mechanisms that underlie the effects of these drugs on autophagy are still unclear; however, we do know that different direct and indirect mechanisms apply.

Microtubule inhibitors often block autophagy (Shen et al., 2011). Although autophagosomes are formed throughout the cytoplasm, lysosomes tend to be localized around the nucleus and autophagosomes use the microtubule network to migrate to lysosomes, so disruption of the microtubule dynamics by drugs like vinblastine prevent autophagosome fusion with the lysosome (Köchl et al., 2006). Drugs like chloroquine (CQ) and hydroxychloroquine (HCQ), the agents currently used deliberately to inhibit autophagy in active clinical trials (Amaravadi et al., 2011), are weak bases that accumulate in the lysosomes causing a rise in lysosomal $\mathrm{pH}$ and preventing fusion with autophagosomes. CQ accumulation in lysosomes can also lead to inhibition of mTORC1, leading to induction of genes by the transcription factor TFEB that stimulates lysosomal biogenesis and autophagy (Settembre et al., 2012). Thus, CQ can potentially both inhibit and stimulate autophagy simultaneously.

For the more common case whereby anticancer drugs induce autophagy, different mechanisms apply: some that directly affect the core autophagy machinery and others that regulate autophagy indirectly. Perhaps the best example of anticancer agents that directly affect the core machinery comes from mTOR inhibitors, such as rapamycin, temsirolimus, or similar inhibitors. These drugs induce autophagy by directly inhibiting mTORC1, which is a core negative regulator of the autophagy machinery. This is an example whereby a critical pathway upstream of the core autophagy machinery is targeted by cancer drugs. Other drugs directly target the core autophagy machinery itself. A good example comes from agents, such as ABT737 (4-[4-[[2-(4-chlorophenyl)phenyl]methyl]piperazin1-yl]- $N$-[4-[[(2R)-4-(dimethylamino)-1-phenylsulfanylbutan-2-yl] amino]-3-nitrophenyl] sulfonylbenzamide) and similar drugs, that were designed to inhibit Bcl-2 family proteins by acting as BH3 mimetics (Oltersdorf et al., 2005). These drugs were originally developed to induce apoptosis by inhibiting antiapoptotic proteins, such as Bcl-2, at the mitochondria to control release of cytochrome $\mathrm{c}$ and other mitochondrial proteins that 
regulate apoptosis. However, Bcl-2 also controls autophagy by directly targeting the BECN1 complex that is required for initiating autophagosome formation (Pattingre et al., 2005), and the BH3 mimetics disrupt the interaction between Bcl-2 and BECN1 to induce autophagy (Maiuri et al., 2007). Direct regulation of the BECN1 complex is also responsible for autophagy induction by tyrosine kinase inhibitors, such as erlotinib, that target the epidermal growth factor receptor (EGFR) (Wei et al., 2013). The underlying mechanism in this case involves inhibition of direct phosphorylation of BECN1 by EGFR that changes the BECN1 interactome to switch it from an autophagy-inhibiting to an autophagy-inducing state. For other cancer drugs that induce autophagy, we have a less clear idea how autophagy is regulated. For example, different kinds of DNA damaging agents activate autophagy, but it is quite unclear how they do so. This is important because better understanding of how different kinds of anticancer agents can induce autophagy may provide a way to selectively interfere with drug-induced autophagy; this might allow selective inhibition of the autophagy that limits anticancer drug action rather than general autophagy.

\section{Effects of Autophagy on Cancer Therapy: Both Positive and Negative}

There have been numerous studies addressing how autophagy affects cancer therapeutics (Tables 1 and 2). Many recent studies have concluded that the role of autophagy is primarily protective and have suggested that autophagy induction is a mechanism of chemoresistance (Levy and Thorburn, 2011; Maycotte and Thorburn, 2011). This is the underlying basis for the ongoing clinical trials where autophagy is being deliberately targeted; they attempt to inhibit autophagy as part of a combination therapy strategy with other cancer drugs. However, there is no blanket agreement on this. In many cases it has also been concluded that the opposite holds, i.e., that autophagy is not protective but is actually necessary for the antitumor effect of the drug that is being tested and consequently inhibition of autophagy reduces tumor cell death and increases tumor growth after drug treatment. For example, a recent paper concluded that EGFR inhibition by drugs like erlotinib (a standard therapy in EGFR-mutant lung cancer) requires autophagy to be induced to maximize inhibition of lung tumor growth (Wei et al., 2013). Obviously, such conflicting results create a problem, because the implications for whether interventions should be designed to stimulate or inhibit autophagy are also in conflict. For, example, a terminated clinical trial (NCT01026844) and an active clinical trial as of the time of writing (NCT00809237) both propose to use EGFR inhibitors with the autophagy inhibitor HCQ in nonsmall cell lung cancer. If recent conclusions about EGFR regulation of autophagy (Wei et al., 2013) are correct, this approach might be counterproductive.

An informative example comes from consideration of tamoxifen, which is an antiestrogen that is a standard therapy for estrogen receptor positive breast cancer. Although a

TABLE 1

Summary of studies showing enhanced response of cytotoxic chemotherapy in combination with pharmacologic inhibition of autophagy

\begin{tabular}{|c|c|c|c|c|}
\hline $\begin{array}{l}\text { Therapeutic } \\
\text { Agent }\end{array}$ & Model & $\begin{array}{l}\text { Autophagy } \\
\text { Inhibition }\end{array}$ & Response & Reference \\
\hline Temozolomide & Human malignant glioma cell lines & $\begin{array}{l}\text { 3-Methyladenine } \\
\text { Bafilomycin A }\end{array}$ & $\begin{array}{l}\text { Decreased cytotoxicity } \\
\text { Increased cytotoxicity }\end{array}$ & Kanzawa et al., 2004 \\
\hline 5-Fluorouracil & Human colon cancer cell lines & 3-Methyladenine & Increased apoptosis & $\mathrm{Li}$ et al., 2009 \\
\hline 5-Fluorouracil & Human colon cancer cell lines and xenograft & & Increased cytotoxicity & $\mathrm{Li}$ et al., 2010 \\
\hline 5-Fluorouracil & Human colon cancer cell line (HT29) & Chloroquine & Increased cytotoxicity & Sasaki et al., 2010 \\
\hline 5-Fluorouracil & Human NSCLC cell line (A549) & 3-Methyladenine & Increased apoptosis & Pan et al., 2013 \\
\hline Cisplatin & Esophageal SSC cell line (EC9706) & 3-Methyladenine & Increased apoptosis & Liu et al., 2011a \\
\hline Cisplatin & Human cholangiocarcinoma cell lines & $\begin{array}{l}\text { 3-Methyladenine } \\
\text { Wortmannin }\end{array}$ & Increased cytotoxicity & Hou et al., 2011 \\
\hline Cisplatin & Human cervical cancer cell line (HeLa) & $\begin{array}{l}\text { 3-Methyladenine } \\
\text { Chloroquine }\end{array}$ & Increased apoptosis & Xu et al., 2012 \\
\hline Paclitaxel & Human NSLC cell line (A549) & 3-Methyladenine & Increased apoptosis & Liu et al., 2013 \\
\hline Etoposide & $\begin{array}{l}\text { Human hepatocellular carcinoma cell } \\
\text { line (HepG2) }\end{array}$ & 3-Methyladenine & Increased cytotoxicity & Xie et al., 2011 \\
\hline Doxorubicin & $\begin{array}{l}\text { Human multiple myeloma cell lines, patient- } \\
\text { derived multiple myeloma cells, human } \\
\text { plasmacytoma xenograft }\end{array}$ & $\begin{array}{l}\text { Hydroxychloroquine } \\
\text { 3-Methyladenine }\end{array}$ & Increased apoptosis & Pan et al., 2011 \\
\hline Epirubicin & Human breast cancer cell line (MCF7) & Bafilomycin A & Increased apoptosis & Sun et al., 2011 \\
\hline Melphalan & $\begin{array}{l}\text { Human multiple myeloma cell lines, patient- } \\
\text { derived multiple myeloma cells, human } \\
\text { plasmacytoma xenograft }\end{array}$ & $\begin{array}{l}\text { Hydroxychloroquine } \\
\text { 3-Methyladenine }\end{array}$ & Increased apoptosis & Pan et al., 2011 \\
\hline Topotecan & Human NSLC cell line (A549) & Chloroquine & Increased cytotoxicity & Wang et al., 2011 \\
\hline Camptothecin & Human breast cancer cell lines & $\begin{array}{l}\text { Wortmannin } \\
\text { 3-Methlyadenine } \\
\text { Bafilomycin A }\end{array}$ & $\begin{array}{l}\text { Increased apoptosis in } \\
\text { selective cell lines }\end{array}$ & Abedin et al., 2007 \\
\hline
\end{tabular}


TABLE 2

Summary of studies combining molecularly targeted agents with pharmacologic inhibition of autophagy

\begin{tabular}{|c|c|c|c|c|}
\hline Therapeutic Agent & Model & $\begin{array}{l}\text { Autophagy } \\
\text { Inhibition }\end{array}$ & Response & Reference \\
\hline Imatinib & $\begin{array}{l}\text { Human Philadelphia chromosome positive } \\
\text { CML cells }\end{array}$ & Chloroquine & Increased cytotoxicity & Bellodi et al., 2009 \\
\hline HDACi/vorinostat & Human colon cancer cells and xenografts & Chloroquine & $\begin{array}{l}\text { Increased cytotoxicity } \\
\text { Decreased growth }\end{array}$ & Carew et al., 2010 \\
\hline HDACi/panobinostat & $\begin{array}{l}\text { Human triple negative breast cancer cells } \\
\text { and xenografts }\end{array}$ & Chloroquine & $\begin{array}{l}\text { Increased cytotoxicity } \\
\text { Decreased tumor growth }\end{array}$ & Rao et al., 2012 \\
\hline HDACi/SAHA & Human CML cell lines and primary CML cells & Chloroquine & Increased cytotoxicity & Carew et al., 2007 \\
\hline HDACi/valproic acid & Human $\mathrm{t}(8 ; 21)$ acute myeloid leukemia cells & Chloroquine & Increased cytotoxicity & Torgersen et al., 2013 \\
\hline HSP90i/DMAG & Human multiple myeloma cell lines & 3-Methyladenine & Increased cytotoxicity & Palacios et al., 2010 \\
\hline Erlotinib & Human glioblastoma cell lines & Chloroquine & Increased cytotoxicity & Eimer et al., 2011 \\
\hline Sorafenib & $\begin{array}{l}\text { Human hepatocellular carcinoma cell lines } \\
\text { and xenografts }\end{array}$ & $\begin{array}{l}\text { Chloroquine } \\
\text { 3-Methyladenine }\end{array}$ & $\begin{array}{l}\text { Increased cytotoxicity and } \\
\text { decreased tumor growth }\end{array}$ & Shi et al., 2011 \\
\hline Sorafenib & $\begin{array}{l}\text { Human hepatocellular carcinoma cell lines } \\
\text { and xenografts }\end{array}$ & Chloroquine & $\begin{array}{l}\text { Increased cytotoxicity and } \\
\text { decreased tumor growth }\end{array}$ & Shimizu et al., 2012 \\
\hline Sunitinib & Rat PC12 cells & $\begin{array}{l}\text { Ammonium } \\
\text { chloride }\end{array}$ & Increased cytotoxicity & Ikeda et al., 2013 \\
\hline AKTi/AZD5363 & $\begin{array}{l}\text { Human prostate cancer cell lines and } \\
\text { xenograft }\end{array}$ & $\begin{array}{l}\text { 3-Methyladenine } \\
\text { Chloroquine } \\
\text { Bafilomycin A }\end{array}$ & $\begin{array}{l}\text { Increased cytotoxicity and } \\
\text { decreased tumor growth }\end{array}$ & Lamoureux et al., 2013 \\
\hline $\begin{array}{l}\text { METi/PHA665752 } \\
\text { and EMD1214063 }\end{array}$ & Human gastric adenocarcinoma cell line & 3-Methyladenine & Increased cytotoxicity & Humbert et al., 2013 \\
\hline Vandetanib & Human glioblastoma cell lines and xenograft & $\begin{array}{l}\text { 3-Methyladenine } \\
\text { Chloroquine }\end{array}$ & $\begin{array}{l}\text { Increased cytotoxicity and } \\
\text { decreased tumor growth }\end{array}$ & Shen et al., 2013 \\
\hline Bevacizumab & Human hepatocellular carcinoma xenografts & Chloroquine & Decreased tumor growth & Guo et al., 2013b \\
\hline Bortezomib & Human multiple myeloma cell line (U266) & $\begin{array}{l}\text { 3-Methyladenine } \\
\text { Bafilomycin A }\end{array}$ & $\begin{array}{l}\text { Decreased cytotoxicity } \\
\text { Increased cytotoxicity }\end{array}$ & Kawaguchi et al., 2011 \\
\hline Bortezomib & $\begin{array}{l}\text { Human hepatocellular carcinoma cell } \\
\text { lines and xenografts }\end{array}$ & Chloroquine & Increased apoptosis & Hui et al., 2012 \\
\hline
\end{tabular}

AKTi, AKT inhibitor; AZD5363, (S)-4-amino- $N$-(1-(4-chlorophenyl)-3-hydroxypropyl)-1-(7H-pyrrolo[2,3-d]pyrimidin-4-yl)piperidine-4-carboxamide; EMD1214063, 3-[1,6-dihydro1-[[3-[5-[(1-methyl-4-piperidinyl)methoxy]-2-pyrimidinyl]phenyl]methyl]-6-oxo-3-pyridazinyl]benzonitrile; HDACi, histone deacetylase inhibitor; PHA665752, (2R)-1-[[5-[(Z)-[5[[(2,6-dichlorophenyl)methyl] sulfonyl]-1,2-dihydro-2-oxo-3H-indol-3-ylidene]methyl]-2,4-dimethyl-1H-pyrrol-3-yl]carbonyl]-2-(1-pyrrolidinylmethyl)pyrrolidine.

highly effective drug, tamoxifen resistance is common, and the mechanism of such resistance is a major area of scientific interest. There are several studies in the literature that examine autophagy in the context of tamoxifen treatment; however, despite this there is no clear picture of the role of autophagy in the context of tamoxifen treatment. The first study about tamoxifen and autophagy concluded that tamoxifen-induced death of MCF7 breast cancer cells was due to autophagy (Bursch et al., 1996). Over the years, numerous other studies have confirmed that tamoxifen does increase autophagy. They have not, however, agreed on whether that autophagy is exerting a cytotoxic or protective effect. Some papers demonstrate that autophagy is required for tamoxifen resistance (Qadir et al., 2008; Samaddar et al., 2008; Cook et al., 2012), i.e., autophagy protects breast cancer cells; however, another study examining tamoxifen resistance mechanisms (also in MCF7 cells) performed a high throughput screen for kinases that confer resistance to tamoxifen in sensitive MCF7 cells. This identified a kinase called HSPB8 and showed that its ability to protect against tamoxifeninduced death was associated with its ability to induce autophagy (Gonzalez-Malerva et al., 2011). The conclusion from this latter study was that tamoxifen resistance could be overcome by increasing autophagy. Thus, there seems general agreement that tamoxifen increases autophagy in MCF7 cells, but in some studies tamoxifen resistance is caused by increased autophagy and in others it is overcome by increased autophagy. A recent paper concluded that tamoxifen-induced autophagy kills cancer cells because of autophagic degradation of Kirsten rat sarcoma viral oncogene homolog (k-RAS) but added that this occurs independent of the estrogen receptor (Kohli et al., 2013). Clearly these incompatible conclusions add little to help determine whether autophagy inhibitors or autophagy enhancers should be investigated in breast cancer patients treated with tamoxifen.

These conflicting conclusions are puzzling. How can the same process kill or protect tumor cells? And what explains the differences between results? A recent study (Gump et al., 2014) provides a precedent (and a molecular explanation) for opposing effects on tumor cell survival for the same stimulus in different contexts. In this study, our group examined autophagy in response to death receptor agonists, Fas Ligand (FasL), and tumor necrosis like apoptosis-inducing ligand (TRAIL). Both these canonical apoptosis inducers are relevant for cancer therapy. TRAIL receptor agonists are being tested as anticancer agents (Dimberg et al., 2013), and although FasL cannot be administered systemically as a cancer therapeutic, other anticancer agents work, in part through activation of Fas/CD95-dependent signaling (Park et al., 2008; Hamed et al., 2013), and targeting of Fas/CD95 agonists to tumor cells by various means has been proposed as a way to selectively kill tumor cells (for a recent review, see Villa-Morales and Fernández-Piqueras, 2012). In our recent study (Gump et al., 2014), we found that autophagy variation in a population of tumor cells predicts which cells will live and which will die when Fas or TRAIL receptors are activated. Surprisingly, however, in the same population of cells, high autophagy caused increased sensitivity to Fas-induced apoptosis but reduced sensitivity to TRAIL-induced apoptosis. Moreover, this effect whereby autophagy promotes Fas-induced 
apoptosis was cell type-specific. In some cells, autophagy promoted Fas-induced apoptosis, whereas in others it inhibited Fas-induced apoptosis. The molecular explanation is that a cell type-specific negative regulator of Fas-induced apoptosis (the protein phosphatase PTPN13, also known as FAP1, which does not affect TRAIL receptor signaling) was degraded by selective autophagy, and this was necessary and sufficient to explain the proapoptotic effect only in some tumor cells. Thus, autophagy can have opposing effects on two very similar death stimuli (FasL and TRAIL), even in the same cells treated at the same time. Furthermore, it can also have opposing effects on apoptosis by the same stimulus in different cells. This is due to selective degradation of a protein that regulates a specific apoptosis pathway.

It is possible that similar cell type and stimulus-specific mechanisms underlie at least some of the conflicting conclusions regarding whether autophagy promotes or inhibits killing by anticancer agents in different contexts-even different results in the same cell line such as is seen with MCF7 cells treated with tamoxifen could be due to differences between different strains of the same tumor cell line that arose during selection for acquired resistance. If this is the case, then it will be important to have both a very good understanding of the underlying mechanisms by which a drug kills cancer cells and also effective biomarkers to identify different responses if we aim to manipulate autophagy during cancer treatment to boost the effect of any given drug.

The mechanism whereby autophagy was shown to promote FasL but not TRAIL-induced tumor cell killing involved degradation of a specific autophagy target. This makes sense because autophagy degrades cellular material, and in this case it degraded a negative regulator of a signaling pathway to cause better activation of that pathway. However, we more commonly think of autophagy as protecting cells and its inhibition as leading to increased apoptosis. Perhaps surprisingly, similar molecular mechanisms whereby autophagy protects against apoptosis are unclear, i.e., we have little evidence of specific autophagy cargos whose degradation can explain why autophagy inhibition would promote tumor cell killing (Yonekawa and Thorburn, 2013). One example is specific to TRAIL-induced death, where it has been shown that autophagy can degrade activated caspase-8 to limit activation of the TRAIL apoptosis pathway (Hou et al., 2010). However, most apoptotic stimuli do not require caspase-8, so there presumably may exist other, more general, mechanisms by which autophagic degradation of specific cargos that themselves are positive regulators of apoptosis would reduce the efficiency of the core apoptosis machinery. An important implication of this is that, as with the FasL effects described above, these mechanisms may apply to some death stimuli but not others. The death-promoting effects of autophagy inhibition may also have nothing to do with preventing autophagy from degrading a positive regulator but instead may be due to a toxic effect of arresting the autophagy process and accumulating autophagosomes that do not fuse with lysosomes (Tang et al., 2012). It is not obvious why accumulation of autophagosomes would be toxic. One potential explanation is that the autophagosomal membrane can serve as a scaffold upon which dimerization and activation of caspase- 8 takes place to promote apoptosis (Young et al., 2012); increased numbers of autophagosomes would presumably make this type of event easier.
Proapoptotic effects of autophagy can occur in a stimulusspecific manner. For example, a series of studies from the Dent laboratory have examined effects of the multikinase inhibitor sorafenib in combination with other drugs and found that in some cases autophagy was protective but in others a toxic form of autophagy was induced (Walker et al., 2009; Bareford et al., 2011, 2012).

\section{Cell Autonomous and Nonautonomous Effects of Autophagy on Cancer Therapy}

The mechanisms discussed above assume that the important effects of autophagy in terms of determining the response to cancer therapy are cell autonomous. That is, more or less autophagy in the tumor cell determines the likelihood of that cell living or dying and thus affecting the success or failure of a therapy intended to reduce tumor growth. However, in a real tumor, each cell does not behave autonomously; neighboring cells, both tumor cells and normal cells in the tumor microenvironment, have profound effects on tumor behavior and response to therapy.

A number of studies show that autophagy regulates the ability of cells to release signaling molecules. For example, we found that autophagy in tumor cells controls whether a dying cell releases HMGB1 (Thorburn et al., 2009). Extracellular HMGB1 can itself regulate autophagy through its receptor RAGE as well as through intracellular signaling (Tang et al., 2010a,b), and this can, in turn, affect chemotherapy resistance (Liu et al., 2011b). Thus, autophagy or lack of autophagy in one tumor cell could potentially affect the behavior of other tumor cells that are responding to the autophagy-dependent release of HMGB1. HMGB1 may also determine the response of the immune system to dying cells and affect cell growth and metastasis (Ellerman et al., 2007); thus, modulation of autophagy leading to altered release of HMGB1 or similar proteins could affect growth of neighboring tumor cells. Other signaling molecules that affect growth, survival, and invasion, such as interleukin (IL)-6, can also be secreted through autophagy-dependent mechanisms (Young et al., 2009), and IL- $1 \beta$ is released by a noncanonical secretory pathway that requires the autophagy machinery (Dupont et al., 2011). Thus, we are just starting to realize that autophagy can affect how cells signal to each other by controlling secretion of what might be a wide spectrum of signaling molecules that could affect the behavior of neighboring cells.

These autophagy-dependent effects on secretion can have a profound effect on cancer treatment by affecting how other tumor cells respond to the dying cells. The best understood case involves whether dying tumor cells undergo immunogenic or nonimmunogenic death. It seems unlikely that any anticancer drug could work with $100 \%$ efficiency, i.e., to kill every single cancer cell. It has been suggested that curative cancer therapy requires not only that we find ways to kill as many cancer cells as possible but that the dying cancer cells also activate an antitumor immune response (Zitvogel et al., 2008), raising the question of what governs whether a dying cell is immunogenic or not (Tesniere et al., 2008). A number of characteristics are required for immunogenic death, including the exposure of calreticulin on the dying cells and release of proteins like HMGB1 as well as ATP. Importantly, these effects are also controlled by autophagy. It has been shown that autophagy in dying cells is required for the release of 
ATP necessary for mounting an immune response to the dying cell after treatment with cytotoxic chemotherapy (Michaud et al., 2011). These autophagy-dependent effects can have profound impact on the efficiency of cancer therapy. For example, a recent study demonstrated that autophagy inhibition could radiosensitize in vitro and in vivo in immunedeficient mice but autophagy inhibition led to reduced response to ionizing radiation treatment in immune competent mice (Ko et al., 2014). This suggests that the requirement for autophagy in dying cells to prime the immune system overrides any benefit from greater cell-autonomous killing activity caused by autophagy inhibition. The underlying mechanism that is important here is autophagy-dependent release of ATP because it was possible to rescue the immunogenic effect by inhibiting ATPase activity in the tumor to raise extracellular ATP levels artificially. Autophagy also has broader functions that affect antitumor immune responses; for example, it is required for cross presentation of tumor antigens in response to adjuvants, such as the vitamin $\mathrm{E}$ derivative $\alpha$-tocopheryloxyacetic acid, that are able to improve antitumor immune responses (Li et al., 2012).

The important point is that although most effort so far has been focused on developing and testing a rationale for inhibiting autophagy to increase autonomous tumor cell killing, this may be stymied in the real world by inadvertently reducing the effectiveness of other nontumor cell autonomous effects through reduced ability to mount an effective immune response to the tumor. This may be due to both less effective antigen presentation and less effective stimulation of the immune response from released immunogenic molecules. At the same time, autophagy is also capable of regulating the release of signaling proteins, such as IL-6 or HMGB1, which mediate paracrine growth and invasion signals. It is not obvious how the balance of these effects would affect the outcome of treatment, and it seems quite likely that the relative importance could vary in different contexts. A critical practical problem is that these effects may not be observed by many experimental studies, as dramatically demonstrated by different overall effects on immune-deficient and immunecompetent mice (Michaud et al., 2011; Ko et al., 2014). This means it will be important to determine what the most important effects are likely to be if one wants to design rational interventions where autophagy is manipulated in a therapeutic context and to potentially develop more clinically relevant preclinical cancer models for evaluating autophagy inhibition.

Notwithstanding the fact that one might fairly interpret all the above as so confusing that it could be viewed as a manifesto to do nothing when it comes to manipulation of autophagy in cancer therapy, there are already some three dozen clinical trials where deliberate attempts to inhibit autophagy (in all cases so far this has been done with CQ or, more commonly, HCQ) are being explored in combination with a wide variety of other agents and in a broad spectrum of tumor types. Given this situation, how can we maximize the likelihood that these interventions will be successful?

\section{Are We Using the Best Drugs to Inhibit Autophagy?}

The first thing to consider is that the drugs we are using to block autophagy are probably not optimal. HCQ and CQ are being used for these purposes because they are approved, relatively safe, and inexpensive. CQ and HCQ both work to inhibit autophagy by inhibiting lysosomal function, but they also do other things as well. Indeed, it has been demonstrated that chemosensitization by CQ can occur by autophagyindependent mechanisms as well as through autophagy inhibition (Maycotte et al., 2012), and the overall effectiveness of CQ-based autophagy inhibition in preclinical studies has been quite variable (Bristol et al., 2013). Thus, there is great interest in developing more effective autophagy inhibitors. Such agents have been shown to be more effective autophagy inhibitors and more effective antitumor agents (McAfee et al., 2012). In the meantime, the first clinical trials with the currently available drugs (i.e., HCQ) will be reported soon. Our group recently completed a phase I study of HCQ and doxorubicin in dogs with spontaneous non-Hodgkin's lymphoma (Barnard RA, Wittenburg LA, Amaravadi RK, Gustafson DL, Thorburn A, and Thamm DH, submitted manuscript). This study indicated that autophagy can indeed be blocked by HCQ treatment in cancer patients and provided evidence that this inhibition could be beneficial in terms of clinical response. However, important limitations to HCQ-based therapies were identified. For example, we found that although HCQ accumulated in tumor tissue, the concentration of the drug in the tumor was not related to levels in the blood and inhibition of autophagy (e.g., as determined by increased levels of LC3-II or the autophagy substrate p62/SQSTM in cells) in blood cells did not necessarily correlate with autophagy inhibition in tumor tissue. These data strengthen the idea that we need better autophagy inhibitors, particularly those with better biodistribution and ability to target tumor tissues if we are to be successful in targeting autophagy in cancer patients, and further call into question the utility of nontumor surrogates like blood cells for evaluating pharmacokinetic and pharmacodynamic endpoints.

\section{How Will We Know If We Have Affected Autophagy in a Patient's Tumor?}

Another problem when we consider the realities of treating patients and determining how autophagy affects their response to treatment relates to what we should measure to know if autophagy is indeed being blocked (or stimulated) in vivo. Autophagy is by nature a dynamic process-autophagosomes are formed, engulf cargo either specifically or nonspecifically, then fuse with lysosomes, and the contents along with autophagosome markers like LC3-II are degraded and recycled. A major problem for the field is that although we now have methods to measure this dynamic process in vitro, we have very poor ways to assess this dynamism in a living organism (especially a human). One common misunderstanding in the literature even for in vitro studies comes from the fact that increased numbers of autophagosomes, e.g., as determined by counting LC3 foci in a cell, could mean that autophagy is increased (i.e., more atophagosomes are being made) or that it is being decreased (i.e., fewer autophagosomes are fusing with lysosomes). In a tissue culture dish, we can rigorously discriminate between these possibilities by deliberately blocking fusion with lysosomes and monitoring an increase in LC3-II levels or foci. Alternatively, we can use techniques like the tandem tagged mCherry-GFP-LC3 molecule and analysis of 
the ratio of red to green fluorescence in both living and fixed cells (Gump et al., 2014). Unfortunately, these approaches are not feasible in a cancer patient, making it inherently difficult to determine if an intervention affected autophagy or not. Approaches that are feasible with, for example, a posttreatment biopsy sample are immunohistochemical staining, e.g., for LC3 puncta (Ladoire et al., 2012) or for a known autophagy cargo protein like p62/SQSTM. Additionally, one can use electron microscopy to assess autophagosomes and autolysosomes in tumor tissue. As noted above, these assays are not optimal-for example, LC3 levels or foci numbers are not a good way of determining whether autophagy has been inhibited. One might imagine that analysis of the level of an autophagy cargo, such as p62/SQSTM, would be a better test of whether autophagy was increased or decreased. However, a problem here is that, although p62 protein levels are indeed regulated by autophagy, its transcription is also controlled by diverse stimuli especially reactive oxygen species, which means that one must perform rigorous controls to definitively use p62 levels as an indicator of autophagy levels (Bjørkøy et al., 2009). Obviously such approaches are, like the optimal analysis of LC3, not feasible in human tissues. We need better ways to monitor the amount of autophagy and autophagic flux in animals and especially in humans so that we can develop useful pharmacodynamic markers for clinical studies of autophagy manipulation.

\section{Some Tumors Are More Dependent on Autophagy than Others}

Autophagy is more important for some tumor cells than for others. This idea has been called "autophagy addiction" (Guo et al., 2011) and identifies autophagy as a novel therapeutic target for some tumors while raising the question, which ones? The Debnath (Lock et al., 2011), White (Guo et al., 2011), and Kimmelman (Yang et al., 2011) laboratories reported that mutant RAS leads to higher autophagy that promotes efficient metabolism to support tumor cell growth, particularly under stressful conditions as found in many tumors. This suggests that RAS mutation or activation of the RAS pathway might identify tumors where autophagy inhibition would be useful (Mancias and Kimmelman, 2011). Supporting this idea, two recent studies show that genetic inhibition of autophagy in vivo has profound effects on lung tumors driven by mutant RAS (Guo et al., 2013a) and v-raf murine sarcoma viral oncogene homolog $\mathrm{B}(B R A F)$ (Strohecker et al., 2013). Importantly, these studies also show that ATG7 knockout results in accumulation of defective mitochondria, reduces tumor burden, and interestingly, changes the histotype of tumor that develops from adenocarcinomas to a more benign oncocytoma. These data suggest that RAS pathway-driven tumors may be a good choice for autophagy inhibition therapy. However, it is unclear whether all tumor cells with mutant RAS will respond to autophagy inhibition therapy. In some cases RAS-driven autophagy appears to limit tumor cell growth rather than promote it (Elgendy et al., 2011), and in this situation, it would presumably be better to promote rather than inhibit autophagy. Moreover a recent paper from Kevin Ryan's group studying k-RAS-driven pancreas cancer found that genetic inhibition of autophagy (by ATG5 or ATG7 knockout) inhibited tumor growth when p53 is wild type but stimulated tumor growth in RAS mutant, p53 null cells (Rosenfeldt et al., 2013). This work implies that even for RAS-driven cancers in mice, the response to autophagy inhibition is highly context dependent. It is also unknown if tumor cells where the RAS pathway is not mutated can also be autophagy addicted. Furthermore, we do not know if autophagy-addicted versus nonaddicted tumor cells respond better in terms of chemosensitization when autophagy is inhibited, i.e., if tumor cells that rely more on autophagy will also show increased chemosensitization to other agents. However, although there is still much to learn about differences between tumors in terms of autophagy addiction, it seems clear that it is unlikely that all tumors will behave exactly the same when autophagy is manipulated. This implies that some people with cancer may benefit more from autophagy manipulation/inhibition than others, and a major effort will be to find ways to identify these patients. In the various autophagy inhibition clinical trials that are ongoing just now, no strategy for patient selection is being pursued.

\section{Summary and Problems To Be Solved}

Autophagy is affected by and also affects diverse cancer therapies; however, these effects are not always the sameindeed, they are often diametrically opposed. Sometimes cancer therapeutics induce autophagy, and sometimes they inhibit it. Sometimes autophagy protects tumor cells against cancer therapy, and sometimes it is required for the therapy to kill the cancer cell. However, we are starting to detect patterns and are making rapid progress in understanding the underlying molecular mechanisms that govern these effects. This allows us to at least begin to develop rational approaches to manipulate autophagy for clinical benefit. In our view, the most important priorities just now for autophagy research as it relates to cancer therapy are to find ways to identify which tumors will be most effectively treated by autophagy manipulation (usually this will mean autophagy inhibition). Can we develop biomarkers that will predict autophagy dependency and addiction, and are these the best tumors to treat? Is the RAS pathway the most important marker of such autophagy addiction, or are some other tumor cells also dependent on this process? How does the balance between pro- and antitumorigenic effects of autophagy involving the immune system and other tumor cell autonomous and nonautonomous influences affect long-term outcomes of treatment? Additionally, we need to determine which drugs will work best with autophagy inhibition. Will drugs like the mTOR inhibitors that directly activate autophagy be more sensitive to autophagy inhibition than drugs that only affect autophagy indirectly? Can we develop better drugs to inhibit autophagy? And, can we work out better ways to measure their effects on this process that can be applied in a clinical setting? As the first clinical studies that are intended to deliberately target autophagy in cancer treatment are completed and reported, answers to these and related questions will be critical for moving the field forward.

\section{Acknowledgments}

The authors thank the laboratory personnel in each of the laboratories whose research and scientific input has helped refine the ideas presented here. 


\section{Authorship Contributions}

Wrote or contributed to the writing of the manuscript: Thorburn, Thamm, Gustafson.

\section{References}

Abedin MJ, Wang D, McDonnell MA, Lehmann U, and Kelekar A (2007) Autophagy delays apoptotic death in breast cancer cells following DNA damage. Cell Death Differ 14:500-510.

Amaravadi RK, Lippincott-Schwartz J, Yin X-M, Weiss WA, Takebe N, Timmer W, DiPaola RS, Lotze MT, and White E (2011) Principles and current strategies for targeting autophagy for cancer treatment. Clin Cancer Res 17:654-666.

Amaravadi RK, Yu D, Lum JJ, Bui T, Christophorou MA, Evan GI, Thomas-Tikhonenko A, and Thompson CB (2007) Autophagy inhibition enhances therapy-induced apoptosis in a Myc-induced model of lymphoma. J Clin Invest 117:326-336.

Bareford MD, Hamed HA, Allegood J, Cruickshanks N, Poklepovic A, Park MA, Ogretmen B, Spiegel S, Grant S, and Dent P (2012) Sorafenib and pemetrexed toxicity in cancer cells is mediated via SRC-ERK signaling. Cancer Biol Ther 13:793-803.

Bareford MD, Park MA, Yacoub A, Hamed HA, Tang Y, Cruickshanks N, Eulitt P, Hubbard N, Tye G, and Burow ME et al. (2011) Sorafenib enhances pemetrexed cytotoxicity through an autophagy-dependent mechanism in cancer cells. Cancer Res 71:4955-4967.

Bellodi C, Lidonnici MR, Hamilton A, Helgason GV, Soliera AR, Ronchetti M, Galavotti S, Young KW, Selmi T, and Yacobi R et al. (2009) Targeting autophagy potentiates tyrosine kinase inhibitor-induced cell death in Philadelphia chromosome-positive cells, including primary CML stem cells. J Clin Invest 119:1109-1123.

Birgisdottir AB, Lamark T, and Johansen T (2013) The LIR motif-crucial for selective autophagy. J Cell Sci 126:3237-3247.

Bjørkøy G, Lamark T, Pankiv S, Øvervatn A, Brech A, and Johansen T (2009) Monitoring autophagic degradation of p62/SQSTM1. Methods Enzymol 452: 181-197.

Bristol ML, Emery SM, Maycotte P, Thorburn A, Chakradeo S, and Gewirtz DA (2013) Autophagy inhibition for chemosensitization and radiosensitization in cancer: do the preclinical data support this therapeutic strategy? J Pharmacol Exp Ther 344:544-552.

Bursch W, Ellinger A, Kienzl H, Török L, Pandey S, Sikorska M, Walker R, and Hermann RS (1996) Active cell death induced by the anti-estrogens tamoxifen and ICI 164384 in human mammary carcinoma cells (MCF-7) in culture: the role of autophagy. Carcinogenesis 17:1595-1607.

Carew JS, Medina EC, Esquivel JA, 2nd, Mahalingam D, Swords R, Kelly K, Zhang H, Huang P, Mita AC, and Mita MM et al. (2010) Autophagy inhibition enhance vorinostat-induced apoptosis via ubiquitinated protein accumulation. J Cell Mol Med 14:2448-2459.

Carew JS, Nawrocki ST, Kahue CN, Zhang H, Yang C, Chung L, Houghton JA, Huang P, Giles FJ, and Cleveland JL (2007) Targeting autophagy augments the anticancer activity of the histone deacetylase inhibitor SAHA to overcome Bcr-Ablmediated drug resistance. Blood 110:313-322.

Cook KL, Shajahan AN, Wärri A, Jin L, Hilakivi-Clarke LA, and Clarke R (2012) Glucose-regulated protein 78 controls cross-talk between apoptosis and autophagy to determine antiestrogen responsiveness. Cancer Res 72:3337-3349.

Dimberg LY, Anderson CK, Camidge R, Behbakht K, Thorburn A, and Ford HL (2013) On the TRAIL to successful cancer therapy? Predicting and counteracting resistance against TRAIL-based therapeutics. Oncogene 32:1341-1350.

Dupont N, Jiang S, Pilli M, Ornatowski W, Bhattacharya D, and Deretic V (2011) Autophagy-based unconventional secretory pathway for extracellular delivery of IL-1ß. EMBO J 30:4701-4711.

Eimer S, Belaud-Rotureau MA, Airiau K, Jeanneteau M, Laharanne E, Véron N, Vital A, Loiseau H, Merlio JP, and Belloc F (2011) Autophagy inhibition cooperates with erlotinib to induce glioblastoma cell death. Cancer Biol Ther 11:1017-1027.

Elgendy M, Sheridan C, Brumatti G, and Martin SJ (2011) Oncogenic Ras-induced expression of Noxa and Beclin-1 promotes autophagic cell death and limits clonogenic survival. Mol Cell 42:23-35.

Ellerman JE, Brown CK, de Vera M, Zeh HJ, Billiar T, Rubartelli A, and Lotze MT (2007) Masquerader: high mobility group box-1 and cancer. Clin Cancer Res 13 $2836-2848$

Ganley IG, Wong P-M, Gammoh N, and Jiang X (2011) Distinct autophagosomallysosomal fusion mechanism revealed by thapsigargin-induced autophagy arrest. Mol Cell 42:731-743.

Gonzalez-Malerva L, Park J, Zou L, Hu Y, Moradpour Z, Pearlberg J, Sawyer J, Stevens H, Harlow E, and LaBaer J (2011) High-throughput ectopic expression screen for tamoxifen resistance identifies an atypical kinase that blocks autophagy. Proc Natl Acad Sci USA 108:2058-2063.

Gump JM, Staskiewicz L, Morgan MJ, Bamberg A, Riches DWH, and Thorburn A (2014) Autophagy variation within a cell population determines cell fate through selective degradation of Fap-1. Nat Cell Biol 16:47-54.

Guo JY, Chen H-Y, Mathew R, Fan J, Strohecker AM, Karsli-Uzunbas G, Kamphorst JJ, Chen G, Lemons JMS, and Karantza V et al. (2011) Activated Ras requires autophagy to maintain oxidative metabolism and tumorigenesis. Genes Dev 25:460-470.

Guo JY, Karsli-Uzunbas G, Mathew R, Aisner SC, Kamphorst JJ, Strohecker AM, Chen G, Price S, Lu W, and Teng X et al. (2013a) Autophagy suppresses progression of K-ras-induced lung tumors to oncocytomas and maintains lipid homeostasis. Genes Dev 27:1447-1461.

Guo XL, Li D, Hu F, Song JR, Zhang SS, Deng WJ, Sun K, Zhao QD, Xie XQ, and Song YJ et al. (2012) Targeting autophagy potentiates chemotherapy-induced apoptosis and proliferation inhibition in hepatocarcinoma cells. Cancer Lett 320 : 171-179.

Guo XL, Li D, Sun K, Wang J, Liu Y, Song JR, Zhao QD, Zhang SS, Deng WJ, and Zhao X et al. (2013b) Inhibition of autophagy enhances anticancer effects of bevacizumab in hepatocarcinoma. J Mol Med (Berl) 91:473-483.
Hamed HA, Das SK, Sokhi UK, Park MA, Cruickshanks N, Archer K, Ogretmen B, Grant S, Sarkar D, and Fisher PB et al. (2013) Combining histone deacetylase inhibitors with MDA-7/IL-24 enhances killing of renal carcinoma cells. Cancer Biol Ther 14:1039-1049.

Hou W, Han J, Lu C, Goldstein LA, and Rabinowich H (2010) Autophagic degradation of active caspase-8: a crosstalk mechanism between autophagy and apoptosis. Autophagy 6:891-900.

Hou YJ, Dong LW, Tan YX, Yang GZ, Pan YF, Li Z, Tang L, Wang M, Wang Q, and Wang HY (2011) Inhibition of active autophagy induces apoptosis and increases chemosensitivity in cholangiocarcinoma. Lab Invest 91:1146-1157.

Hui B, Shi YH, Ding ZB, Zhou J, Gu CY, Peng YF, Yang H, Liu WR, Shi GM, and Fan $\mathrm{J}$ (2012) Proteasome inhibitor interacts synergistically with autophagy inhibitor to suppress proliferation and induce apoptosis in hepatocellular carcinoma. Cancer 118:5560-5571.

Humbert M, Medová M, Aebersold DM, Blaukat A, Bladt F, Fey MF, Zimmer Y, and Tschan MP (2013) Protective autophagy is involved in resistance towards MET inhibitors in human gastric adenocarcinoma cells. Biochem Biophys Res Commun 431:264-269.

Ikeda T, Ishii KA, Saito Y, Miura M, Otagiri A, Kawakami Y, Shimano H, Hara H, and Takekoshi K (2013) Inhibition of autophagy enhances sunitinib-induced cytotoxicity in rat pheochromocytoma PC12 cells. J Pharmacol Sci 121:67-73.

Kang R, Wang ZH, Wang BQ, Zhang CM, Gao W, Feng Y, Bai T, Zhang HL, Huang$\mathrm{Pu} \mathrm{H}$, and Wen SX (2012) Inhibition of autophagy-potentiated chemosensitivity to cisplatin in laryngeal cancer Hep-2 cells. Am J Otolaryngol 33:678-684.

Kanzawa T, Germano IM, Komata T, Ito H, Kondo Y, and Kondo S (2004) Role of autophagy in temozolomide-induced cytotoxicity for malignant glioma cells. Cell Death Differ 11:448-457.

Kawaguchi T, Miyazawa K, Moriya S, Ohtomo T, Che XF, Naito M, Itoh M, and Tomoda A (2011) Combined treatment with bortezomib plus bafilomycin A1 enhances the cytocidal effect and induces endoplasmic reticulum stress in U266 myeloma cells: crosstalk among proteasome, autophagy-lysosome and ER stress. Int $J$ Oncol 38:643-654.

Kimmelman AC (2011) The dynamic nature of autophagy in cancer. Genes Dev $\mathbf{2 5}$ 1999-2010.

Ko A, Kanehisa A, Martins I, Senovilla L, Chargari C, Dugue D, Mariño G, Kepp O, Michaud M, and Perfettini J-L et al. (2014) Autophagy inhibition radiosensitizes in vitro, yet reduces radioresponses in vivo due to deficient immunogenic signalling. Cell Death Differ 21:92-99.

Köchl R, Hu XW, Chan EYW, and Tooze SA (2006) Microtubules facilitate autophagosome formation and fusion of autophagosomes with endosomes. Traffic 7 : 129-145.

Kohli L, Kaza N, Coric T, Byer SJ, Brossier NM, Klocke BJ, Bjornsti M-A, Carroll SL, and Roth KA (2013) 4-Hydroxytamoxifen induces autophagic death through K-Ras degradation. Cancer Res 73:4395-4405.

Kon M, Kiffin R, Koga H, Chapochnick J, Macian F, Varticovski L, and Cuervo AM (2011) Chaperone-mediated autophagy is required for tumor growth. Sci Transl Med 3:109ra117. Kroemer G, Mariño G, and Levine B (2010) Autophagy and the integrated stress response. Mol Cell 40:280-293.

Ladoire S, Chaba K, Martins I, Sukkurwala AQ, Adjemian S, Michaud M, Poirier-Colame V, Andreiuolo F, Galluzzi L, and White E et al. (2012) Immunohistochemical detection of cytoplasmic LC3 puncta in human cancer specimens. Autophagy 8:1175-1184.

Lamoureux F, Thomas C, Crafter C, Kumano M, Zhang F, Davies BR, Gleave ME and Zoubeidi A (2013) Blocked autophagy using lysosomotropic agents sensitizes resistant prostate tumor cells to the novel Akt inhibitor AZD5363. Clin CancerRes 19:833-844.

Levine B and Klionsky DJ (2004) Development by self-digestion: molecular mechanisms and biological functions of autophagy. Dev Cell 6:463-477.

Levy JM and Thorburn A (2011) Targeting autophagy during cancer therapy to improve clinical outcomes. Pharmacol Ther 131:130-141.

Li J, Hou N, Faried A, Tsutsumi S, and Kuwano H (2010) Inhibition of autophagy augments 5-fluorouracil chemotherapy in human colon cancer in vitro and in vivo model. Eur J Cancer 46:1900-1909.

Li J, Hou N, Faried A, Tsutsumi S, Takeuchi T, and Kuwano H (2009) Inhibition of autophagy by 3 -MA enhances the effect of 5 -FU-induced apoptosis in colon cancer cells. Ann Surg Oncol 16:761-771.

Li Y, Hahn T, Garrison K, Cui ZH, Thorburn A, Thorburn J, Hu HM, and Akporiaye ET (2012) The vitamin E analogue $\alpha$-TEA stimulates tumor autophagy and enhances antigen cross-presentation. Cancer Res 72:3535-3545.

Liu D, Yang Y, Liu Q, and Wang J (2011a) Inhibition of autophagy by 3-MA potentiates cisplatin-induced apoptosis in esophageal squamous cell carcinoma cells. Med Oncol 28:105-111.

Liu F, Liu D, Yang Y, and Zhao S (2013) Effect of autophagy inhibition on chemotherapy-induced apoptosis in A549 lung cancer cells. Oncol Lett 5:1261-1265. Liu L, Yang M, Kang R, Wang Z, Zhao Y, Yu Y, Xie M, Yin X, Livesey KM, and Lotze MT et al. (2011b) HMGB1-induced autophagy promotes chemotherapy resistance in leukemia cells. Leukemia 25:23-31.

Lock R, Roy S, Kenific CM, Su JS, Salas E, Ronen SM, and Debnath J (2011) Autophagy facilitates glycolysis during Ras-mediated oncogenic transformation. Mol Biol Cell 22:165-178.

Lorin S, Hamaï A, Mehrpour M, and Codogno P (2013) Autophagy regulation and its role in cancer. Semin Cancer Biol 23:361-379.

Maiuri MC, Le Toumelin G, Criollo A, Rain JC, Gautier F, Juin P, Tasdemir E, Pierron G, Troulinaki K, and Tavernarakis N et al. (2007) Functional and physical interaction between $\mathrm{Bcl}-\mathrm{X}(\mathrm{L})$ and a BH3-like domain in Beclin-1. EMBO J 26 2527-2539.

Mancias JD and Kimmelman AC (2011) Targeting autophagy addiction in cancer. Oncotarget 2:1302-1306.

Maycotte P, Aryal S, Cummings CT, Thorburn J, Morgan MJ, and Thorburn A (2012) Chloroquine sensitizes breast cancer cells to chemotherapy independent of autophagy. Autophagy 8:200-212. 
Maycotte P and Thorburn A (2011) Autophagy and cancer therapy. Cancer Biol Ther 11:127-137.

McAfee Q, Zhang Z, Samanta A, Levi SM, Ma X-H, Piao S, Lynch JP, Uehara T, Sepulveda AR, and Davis LE et al. (2012) Autophagy inhibitor Lys05 has singleagent antitumor activity and reproduces the phenotype of a genetic autophagy deficiency. Proc Natl Acad Sci USA 109:8253-8258.

Michaud M, Martins I, Sukkurwala AQ, Adjemian S, Ma Y, Pellegatti P, Shen S, Kepp O, Scoazec M, and Mignot G et al. (2011) Autophagy-dependent anticancer immune responses induced by chemotherapeutic agents in mice. Science $\mathbf{3 3 4}$ $1573-1577$

Mizushima N (2007) Autophagy: process and function. Genes Dev 21:2861-2873.

Mizushima N, Yoshimori T, and Ohsumi Y (2011) The role of Atg proteins in autophagosome formation. Annu Rev Cell Dev Biol 27:107-132.

Oltersdorf T, Elmore SW, Shoemaker AR, Armstrong RC, Augeri DJ, Belli BA, Bruncko M, Deckwerth TL, Dinges J, and Hajduk PJ et al. (2005) An inhibitor of Bcl-2 family proteins induces regression of solid tumours. Nature 435:677-681.

Palacios C, Martín-Pérez R, López-Pérez AI, Pandiella A, and López-Rivas A (2010) Autophagy inhibition sensitizes multiple myeloma cells to 17-dimethylamino ethylamino-17-demethoxygeldanamycin-induced apoptosis. Leuk Res 34:1533-1538.

Pan X, Zhang X, Sun H, Zhang J, Yan M, and Zhang H (2013) Autophagy inhibition promotes 5-fluorouraci-induced apoptosis by stimulating ROS formation in human non-small cell lung cancer A549 cells. PLoS ONE 8:e56679.

Pan Y, Gao Y, Chen L, Gao G, Dong H, Yang Y, Dong B, and Chen X (2011) Targeting autophagy augments in vitro and in vivo antimyeloma activity of DNA-damaging chemotherapy. Clin Cancer Res 17:3248-3258.

Park MA, Zhang G, Martin AP, Hamed H, Mitchell C, Hylemon PB, Graf M, Rahmani M, Ryan K, and Liu X et al. (2008) Vorinostat and sorafenib increase ER stress, autophagy and apoptosis via ceramide-dependent CD95 and PERK activation. Cancer Biol Ther 7:1648-1662.

Pattingre S, Tassa A, Qu X, Garuti R, Liang XH, Mizushima N, Packer M, Schneider $\mathrm{MD}$, and Levine B (2005) Bcl-2 antiapoptotic proteins inhibit Beclin 1-dependent autophagy. Cell 122:927-939.

Qadir MA, Kwok B, Dragowska WH, To KH, Le D, Bally MB, and Gorski SM (2008) Macroautophagy inhibition sensitizes tamoxifen-resistant breast cancer cells and enhances mitochondrial depolarization. Breast Cancer Res Treat 112:389-403.

Rao R, Balusu R, Fiskus W, Mudunuru U, Venkannagari S, Chauhan L, Smith JE, Hembruff SL, Ha K, and Atadja P et al. (2012) Combination of pan-histone deacetylase inhibitor and autophagy inhibitor exerts superior efficacy against triple-negative human breast cancer cells. Mol Cancer Ther 11:973-983.

Ravikumar B, Sarkar S, Davies JE, Futter M, Garcia-Arencibia M, Green-Thompson ZW, Jimenez-Sanchez M, Korolchuk VI, Lichtenberg M, and Luo S et al. (2010) Regulation of mammalian autophagy in physiology and pathophysiology. Physiol Rev 90:1383-1435.

Rosenfeldt MT, O’Prey J, Morton JP, Nixon C, MacKay G, Mrowinska A, Au A, Rai TS, Zheng L, and Ridgway R et al. (2013) p53 status determines the role of autophagy in pancreatic tumour development. Nature 504:296-300.

Rubinsztein DC, Codogno P, and Levine B (2012) Autophagy modulation as a potential therapeutic target for diverse diseases. Nat Rev Drug Discov 11:709-730.

Rubinsztein DC, Mariño G, and Kroemer G (2011) Autophagy and aging. Cell 146: 682-695.

Samaddar JS, Gaddy VT, Duplantier J, Thandavan SP, Shah M, Smith MJ, Browning D, Rawson J, Smith SB, and Barrett JT et al. (2008) A role for macroautophagy in protection against 4-hydroxytamoxifen-induced cell death and the development of antiestrogen resistance. Mol Cancer Ther 7:2977-2987.

Sasaki K, Tsuno NH, Sunami E, Kawai K, Hongo K, Hiyoshi M, Kaneko M, Murono K, Tada N, and Nirei T et al. (2012) Resistance of colon cancer to 5-fluorouracil may be overcome by combination with chloroquine, an in vivo study. Anticancer Drugs 23:675-682.

Sasaki K, Tsuno NH, Sunami E, Tsurita G, Kawai K, Okaji Y, Nishikawa T, Shuno Y, Hongo K, and Hiyoshi M et al. (2010) Chloroquine potentiates the anti-cancer effect of 5-fluorouracil on colon cancer cells. BMC Cancer 10:370.

Selvakumaran M, Amaravadi RK, Vasilevskaya IA, and O'Dwyer PJ (2013) Autophagy inhibition sensitizes colon cancer cells to antiangiogenic and cytotoxic therapy. Clin Cancer Res 19:2995-3007.

Settembre C, Zoncu R, Medina DL, Vetrini F, Erdin S, Erdin S, Huynh T, Ferron M, Karsenty G, and Vellard MC et al. (2012) A lysosome-to-nucleus signalling mechanism senses and regulates the lysosome via mTOR and TFEB. EMBO $J \mathbf{3 1}$ : $1095-1108$

Shen J, Zheng H, Ruan J, Fang W, Li A, Tian G, Niu X, Luo S, and Zhao P (2013) Autophagy inhibition induces enhanced proapoptotic effects of ZD6474 in glioblastoma. Br J Cancer 109:164-171.

Shen S, Kepp O, Michaud M, Martins I, Minoux H, Métivier D, Maiuri MC, Kroemer RT, and Kroemer G (2011) Association and dissociation of autophagy, apoptosis and necrosis by systematic chemical study. Oncogene 30:4544-4556.

Shi YH, Ding ZB, Zhou J, Hui B, Shi GM, Ke AW, Wang XY, Dai Z, Peng YF, and Gu CY et al. (2011) Targeting autophagy enhances sorafenib lethality for hepatocellular carcinoma via ER stress-related apoptosis. Autophagy 7:1159-1172.
Shimizu S, Takehara T, Hikita H, Kodama T, Tsunematsu H, Miyagi T, Hosui A, Ishida $\mathrm{H}$, Tatsumi $\mathrm{T}$, and Kanto $\mathrm{T}$ et al. (2012) Inhibition of autophagy potentiates the antitumor effect of the multikinase inhibitor sorafenib in hepatocellular carcinoma. Int J Cancer 131:548-557.

Shingu T, Fujiwara K, Bogler O, Akiyama Y, Moritake K, Shinojima N, Tamada Y, Yokoyama $\mathrm{T}$, and Kondo S (2009) Inhibition of autophagy at a late stage enhances imatinib-induced cytotoxicity in human malignant glioma cells. Int J Cancer 124:1060-1071.

Strohecker AM, Guo JY, Karsli-Uzunbas G, Price SM, Chen GJ, Mathew R, McMahon $\mathrm{M}$, and White E (2013) Autophagy sustains mitochondrial glutamine metabolism and growth of BrafV600E-driven lung tumors. Cancer Discov 3:1272-1285.

Sun WL, Chen J, Wang YP, and Zheng H (2011) Autophagy protects breast cancer cells from epirubicin-induced apoptosis and facilitates epirubicin-resistance development. Autophagy 7:1035-1044.

Tang D, Kang R, Cheh CW, Livesey KM, Liang X, Schapiro NE, Benschop R, Sparvero LJ, Amoscato AA, and Tracey KJ et al. (2010a) HMGB1 release and redox regulates autophagy and apoptosis in cancer cells. Oncogene 29:5299-5310.

Tang D, Kang R, Livesey KM, Cheh CW, Farkas A, Loughran P, Hoppe G, Bianchi ME, Tracey KJ, and Zeh HJ, 3rd et al. (2010b) Endogenous HMGB1 regulates autophagy. J Cell Biol 190:881-892.

Tang Y, Hamed HA, Cruickshanks N, Fisher PB, Grant S, and Dent P (2012) Obatoclax and lapatinib interact to induce toxic autophagy through NOXA. Mol Pharmacol 81:527-540.

Tesniere A, Panaretakis T, Kepp O, Apetoh L, Ghiringhelli F, Zitvogel L, and Kroemer G (2008) Molecular characteristics of immunogenic cancer cell death. Cell Death Differ 15:3-12.

Thorburn A and Debnath J (2011) Targeting chaperone-mediated autophagy in cancer. Sci Transl Med 3:109ps145.

Thorburn J, Horita H, Redzic J, Hansen K, Frankel AE, and Thorburn A (2009) Autophagy regulates selective HMGB1 release in tumor cells that are destined to die. Cell Death Differ 16:175-183

Torgersen ML, Engedal N, Bøe SO, Hokland P, and Simonsen A (2013) Targeting autophagy potentiates the apoptotic effect of histone deacetylase inhibitors in $\mathrm{t}(8 ; 21)$ AML cells. Blood 122:2467-2476.

Villa-Morales M and Fernández-Piqueras J (2012) Targeting the Fas/FasL signaling pathway in cancer therapy. Expert Opin Ther Targets 16:85-101.

Walker T, Mitchell C, Park MA, Yacoub A, Graf M, Rahmani M, Houghton PJ, VoelkelJohnson C, Grant S, and Dent P (2009) Sorafenib and vorinostat kill colon cancer cells by CD95-dependent and -independent mechanisms. Mol Pharmacol 76:342-355.

Wang Y, Peng RQ, Li DD, Ding Y, Wu XQ, Zeng YX, Zhu XF, and Zhang XS (2011) Chloroquine enhances the cytotoxicity of topotecan by inhibiting autophagy in lung cancer cells. Chin J Can Cancer 30:690-700.

Wei Y, Zou Z, Becker N, Anderson M, Sumpter R, Xiao G, Kinch L, Koduru P, Christudass CS, and Veltri RW et al. (2013) EGFR-mediated Beclin 1 phosphorylation in autophagy suppression, tumor progression, and tumor chemoresistance. Cell 154:1269-1284.

White E (2012) Deconvoluting the context-dependent role for autophagy in cancer. Nat Rev Cancer 12:401-410.

Xie BS, Zhao HC, Yao SK, Zhuo DX, Jin B, Lv DC, Wu CL, Ma DL, Gao C, and Shu $\mathrm{XM}$ et al. (2011) Autophagy inhibition enhances etoposide-induced cell death in human hepatoma G2 cells. Int J Mol Med 27:599-606.

Xu Y, Yu H, Qin H, Kang J, Yu C, Zhong J, Su J, Li H, and Sun L (2012) Inhibition of autophagy enhances cisplatin cytotoxicity through endoplasmic reticulum stress in human cervical cancer cells. Cancer Lett 314:232-243.

Yang S, Wang X, Contino G, Liesa M, Sahin E, Ying H, Bause A, Li Y, Stommel JM, and Dell'antonio G et al. (2011) Pancreatic cancers require autophagy for tumor growth. Genes Dev 25:717-729.

Yang Z and Klionsky DJ (2010a) Eaten alive: a history of macroautophagy. Nat Cell Biol 12:814-822.

Yang Z and Klionsky DJ (2010b) Mammalian autophagy: core molecular machinery and signaling regulation. Curr Opin Cell Biol 22:124-131.

Yonekawa T and Thorburn A (2013) Autophagy and cell death. Essays Biochem 55: 105-117.

Young AR, Narita M, Ferreira M, Kirschner K, Sadaie M, Darot JF, Tavaré S, Arakawa S, Shimizu S, and Watt FM et al. (2009) Autophagy mediates the mitotic senescence transition. Genes Dev 23:798-803.

Young MM, Takahashi Y, Khan O, Park S, Hori T, Yun J, Sharma AK, Amin S, Hu C-D, and Zhang J et al. (2012) Autophagosomal membrane serves as platform for intracellular death-inducing signaling complex (iDISC)-mediated caspase-8 activation and apoptosis. J Biol Chem 287:12455-12468.

Zitvogel L, Apetoh L, Ghiringhelli F, André F, Tesniere A, and Kroemer G (2008) The anticancer immune response: indispensable for therapeutic success? J Clin Invest 118:1991-2001.

Address correspondence to: Andrew Thorburn, Department of Pharmacology, University of Colorado School of Medicine, Anschutz Medical Campus, Aurora, CO 80045. E-mail: Andrew.Thorburn@ucdenver.edu 